\title{
Development of a self-management program for employees with complaints of the arm, neck, and/ or shoulder: an intervention mapping approach
}

This article was published in the following Dove Press journal:

Journal of Multidisciplinary Healthcare

I July 2015

Number of times this article has been viewed

\author{
Nathan Hutting ${ }^{1,2}$ \\ Sarah I Detaille 2,3 \\ Josephine A Engels ${ }^{2}$ \\ Yvonne F Heerkens ${ }^{2}$ \\ J Bart Staal ${ }^{\prime, 4}$ \\ Maria WG Nijhuis-van \\ der Sanden'
}

'Radboud University Medical Center, Radboud Institute for Health Sciences, the Scientific Institute for Quality of Healthcare, ${ }^{2}$ Hogeschool van Arnhem en Nijmegen (HAN) University of Applied Sciences, Faculty of Health and Social Studies, Research Group Occupation and Health, ${ }^{3} \mathrm{HAN}$ University of Applied Sciences, Department HAN Seneca, ${ }^{4} \mathrm{HAN}$ University of Applied Sciences, Faculty of Health and Social Studies, Research Group Musculoskeletal Rehabilitation, Nijmegen, the Netherlands
Correspondence: Nathan Hutting, HAN University of Applied Sciences, PO Box 6960, 6503 GL Nijmegen,

the Netherlands

Tel +3I 647892426

Email nathan.hutting@han.nl
Purpose: To develop a self-management program with an additional eHealth module, using the six steps of the intervention mapping (IM) protocol, to help employees with complaints of the arm, neck, and/or shoulder (CANS) cope with their problems.

Methods: In Step 1 of the IM protocol, a needs assessment was performed consisting of a review of the Dutch multidisciplinary guidelines on CANS, and of focus group sessions with employees with CANS $(n=15)$ and with relevant experts $(n=17)$. After the needs assessment, the objectives of the intervention and the determinants of self-management at work were formulated (Step 2). Furthermore, theory-based intervention methods and practical strategies were selected (Step 3), and an intervention program (including the eHealth module) was developed (Step 4). Finally, plans for implementation and evaluation of the program were developed (Steps 5 and 6).

Results: Step 1 of the IM protocol revealed that employees with CANS should be stimulated to search for information about the cause of their complaints, about how to deal with their complaints, and in which manner they can influence their complaints themselves. In Step 2, the overall goal of the intervention was defined as "self-management behavior at work" with the aim to alleviate the perceived disability of the participants. Step 3 described how the intervention methods were translated into practical strategies, and goal setting was introduced as an important method for increasing self-efficacy. The product of Step 4 was the final program plan, consisting of 6-weekly group sessions of 2.5 hours each and an eHealth module. In Step 5 , a recruitment plan and course materials were developed, a steering committee was set up, trainers were recruited, and the final program was tested. In Step 6, an evaluation plan was developed, which consists of a randomized controlled trial with a 12-month follow-up period and a qualitative evaluation (interviews) with some of the participants.

Conclusion: This study resulted in a theory- and practice-based self-management program, based on behavioral change theories, guideline-related evidence, and practice-based knowledge that fits the needs of employees with CANS.

Keywords: CANS, work-related upper extremity disorders, WRUED, behavioral change theory, intervention development, perceived disability

\section{Introduction}

Work-related disorders of the upper limbs, also known as work-related upper extremity disorders or complaints of the arm, neck, and/or shoulder (CANS), are an important health problem. ${ }^{1}$ CANS can cause major problems in work participation, which can lead to sickness absence and job loss. ${ }^{2,3}$ In the Netherlands, the point prevalence of chronic complaints (persisting for $>3$ months) due to CANS is $19 \%$; of these patients, $60 \%$ report the use of health care facilities in the past year. ${ }^{1}$ The yearly costs due to CANS have been estimated at $0.5 \%-2 \%$ of the gross national product in the Nordic countries. ${ }^{4}$ 
Thus, work-related neck and upper limb disorders have both a health and substantial socio-economic impact. ${ }^{5}$

In $77 \%$ of the patients, the complaints are located in the upper back/neck/shoulder region, in $25 \%$ in the elbow/ underarm region, in $19 \%$ in the wrist/hand region, and in $42 \%$ the complaints occur in a combination of these regions. ${ }^{6}$ A distinction is usually made between specific CANS (such as epicondylitis, carpal tunnel syndrome) and non-specific CANS. ${ }^{7}$ Non-specific CANS is defined as pain, stiffness, tingling, and/or numbness in the neck, upper back, arms, and/or hands related to work that has persisted for $\geq 2$ weeks. ${ }^{1}$

A recent Cochrane review on conservative interventions for treating work-related CANS found very low-quality evidence showing that exercises did not improve pain compared with no treatment, or with minor intervention controls, or when provided as additional treatment on the short- or longterm follow-up; ${ }^{8}$ these results were similar for recovery, disability, and sick leave. Specific exercises led to increased pain on short-term follow-up compared with general exercises. ${ }^{8}$ The authors also found very low-quality evidence indicating that ergonomic interventions are not effective for pain reduction when compared with no intervention on short-term follow-up, but did decrease pain on long-term follow-up. There was no effect on disability, but sick leave decreased in two of the included studies. None of the ergonomic interventions was more beneficial for any outcome measure when compared with another treatment, or with no treatment, or with placebo. ${ }^{8}$ Behavioral interventions had inconsistent effects on pain and disability, with some subgroups showing benefit and others showing no significant improvement when compared with no treatment, minor intervention controls, or with other behavioral interventions. ${ }^{8}$

Another study showed that the use of a generic selfmanagement program for employees with a chronic somatic disease (intervention group) improved the attitude toward self-management at work (enjoyment) after 8 months $(P=0.03) .{ }^{9}$ An interaction effect showed that low educated workers in the intervention group developed a better physical health quality (using the 12-Item Short Form Health Survey [SF-12]) compared with workers in the control group. The attitude toward self-management at work (importance) improved in the intervention group for older and female workers, and the attitude toward enjoying self-management at work improved for female workers only. ${ }^{9}$

Given the need for intervention programs for people suffering from $\mathrm{CANS}^{7,8,10}$ and the multifactorial (biopsychosocial) origin of CANS, a multicomponent intervention that includes both biomechanical and psychosocial components is recommended. ${ }^{11-13}$ Therefore, we aimed to adapt an existing self-management program for employees with a chronic disease $^{9,14,15}$ to the specific needs of employees with CANS. In addition, by developing an eHealth component, some of the subgroup-specific information can be provided in a tailored way, so that participants can make their own individual choices. In this way, the time during the group meetings can be used more effectively and the information is available for everyone at every moment. ${ }^{16}$ There is evidence that web-based, interactive interventions have a beneficial effect on patient empowerment and/or on physical activity in patients with various chronic conditions. ${ }^{17}$ Moreover, in view of the discontinuity in program use and/or dropout from a study before completion of an internet intervention, ${ }^{18,19}$ plus the potential advantage of face-to-face meetings, the combination of a self-management program with an add-on eHealth component seemed to offer the best possibility for the management of complaints in employees suffering from CANS. Finally, it is a challenge to design an eHealth environment suitable for employees with CANS, who potentially suffer from complaints due to computer use.

In the present study, the intervention mapping (IM) protocol $^{20,21}$ was used to adapt an existing self-management program $^{9,14,15}$ and to develop an eHealth component. IM is a problem- and theory-driven protocol reported to be suitable for the development and implementation of evidenced-based intervention programs. ${ }^{22,23}$ In the current study, we present a detailed overview of how IM was used to modify an existing self-management program to develop an intervention to meet the needs of employees with CANS.

\section{Methods}

IM is a stepwise approach for theory and evidence-based development and implementation of interventions. ${ }^{23}$ The IM protocol consists of six steps (Figure 1). Each step of IM comprises several tasks (Figure 1), and completion of the tasks creates a product that guides the next step. ${ }^{23}$ Program developers use an iterative strategy in which each step is based on the previous steps, moving back and forth between tasks and steps in case new perspectives are gained. ${ }^{23}$

In the present study, IM is used to adapt an existing self-management program ${ }^{9,14,15}$ to fit the needs of employees suffering from chronic ( $>12$ weeks) non-specific CANS, including the development of an eHealth component. The current paper focuses mainly on how Steps 1-4 of the IM protocol were used to adjust the intervention to the needs of the target population. The implementation plan (Step 5) and evaluation plan (Step 6) are only briefly outlined and are described in detail elsewhere. ${ }^{24}$ 


\begin{tabular}{|c|c|c|}
\hline 4 & $\begin{array}{l}\text { Step } 1 \\
\text { Needs assessment }\end{array}$ & $\begin{array}{l}\text { - } \quad \text { Establish a participatory planning group } \\
\text { - } \quad \text { Conduct the needs assessment } \\
\text { - Assess community capacity } \\
\text { - } \quad \text { Specify program goals for health and quality of life }\end{array}$ \\
\hline & $\begin{array}{l}\text { Step } 2 \\
\text { Matrices }\end{array}$ & $\begin{array}{l}\text { - State outcomes for behavior and environmental change } \\
\text { - State performance objectives } \\
\text { - } \quad \text { Select important and changeable determinants } \\
\text { - } \quad \text { Create matrices of change objectives }\end{array}$ \\
\hline & $\begin{array}{l}\text { Step } 3 \\
\text { Theory-based } \\
\text { intervention methods and } \\
\text { practical applications }\end{array}$ & $\begin{array}{l}\text { - } \quad \text { Generate program ideas with the planning group } \\
\text { - Identify theoretical methods } \\
\text { - } \quad \text { Choose program methods } \\
\text { - } \quad \text { Select or design practical applications } \\
\text { - } \quad \text { Ensure that applications address change objectives }\end{array}$ \\
\hline 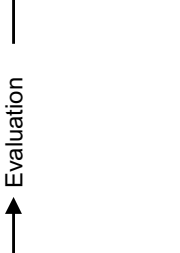 & $\begin{array}{l}\text { Step } 4 \\
\text { Program }\end{array}$ & $\begin{array}{l}\text { - } \text { Consult intended participants and implementers } \\
\text { - } \quad \text { Create program themes, scope, sequence, and materials list } \\
\text { - Prepare design documents } \\
\text { - Review available program materials } \\
\text { - } \quad \text { Draft program materials and protocols } \\
\text { - Pretest program materials and protocols } \\
\text { - Produce materials and protocols }\end{array}$ \\
\hline & $\begin{array}{l}\text { Step } 5 \\
\text { Adoption and } \\
\text { implementation plan }\end{array}$ & $\begin{array}{l}\text { - Identify potential adopters and implementers } \\
\text { - } \quad \text { Reevaluate the planning groups } \\
\text { - State program use outcomes and performance objectives } \\
\text { - } \quad \text { Specify determinants for adoption and implementation } \\
\text { - } \quad \text { Select methods and practical applications } \\
\text { - } \quad \text { Design interventions for adoption and implementation } \\
\end{array}$ \\
\hline & $\begin{array}{l}\text { Step } 6 \\
\text { Evaluation plan }\end{array}$ & $\begin{array}{l}\text { - } \quad \text { Review the program logic model } \\
\text { - Write evaluation questions } \\
\text { - Write evaluation questions for change in determinants } \\
\text { - Write process evaluation questions } \\
\text { - } \quad \text { Sevelop indicators and measures } \\
\text { Specify evaluation design }\end{array}$ \\
\hline & & \\
\hline
\end{tabular}

Figure I Visual representation of the six-step intervention mapping protocol.

Note: Data from Bartholomew et al. Planning Health Promotion Programs. An Intervention Mapping Approach. 3rd ed.; @ 201 I John Wiley and Sons.

\section{Step I: conduct a needs assessment}

First, a needs assessment was conducted to describe the health problem, the impact of the health problem on the patient's quality of life, and the behavioral and environmental determinants of the health problem for the target population. Furthermore, the underlying determinants and the target population were defined, resulting in several desired behavioral outcomes that were selected to be targeted by the intervention. ${ }^{23}$ This resulted in a description of the health problem, its impact on quality of life, behavioral and environmental causes, as well as the determinants of behavioral and environmental causes. ${ }^{23}$ As advised by Bartholomew et $a l,{ }^{23}$ the needs assessment was structured and summarized using the modified Predisposing, Reinforcing and Enabling Constructs in Educational Diagnosis and Evaluation (PRECEDE) model..$^{23,25}$ This model prescribes an analysis of the causation of health problems at multiple levels and the consideration of multiple determinants of health-related behavior and environment. ${ }^{23}$
For the needs assessment, different research methods were used. Firstly, the recently developed Dutch multidisciplinary guideline for non-specific $\mathrm{CANS}^{26}$ was examined to assess current knowledge on CANS and to identify possible causes of CANS and the needs of the target population. Secondly, focus group sessions were held with employees with CANS $(n=15)$ to explore the experienced problems and the needs of the target population. ${ }^{16}$ Thirdly, focus group sessions were held with experts $(n=17)$ in the field of CANS, eHealth, and self-management to acquire their opinions about the needs of employees with CANS, employees' prerequisites for continuing working, and the advantages of using self-management and eHealth for this group..$^{27}$ Also, the experts' opinions on the design and content of the intervention were investigated. All these methods were used to gain insight into the health problem, the behavioral and environmental causes, the determinants of behavior in the environment, and the impact of CANS on work participation and quality of life. ${ }^{23}$ 
The results of the needs assessment were used to determine the content of the new intervention for employees with CANS. The existing self-management training for workers with a chronic disease $e^{9,14,15}$ was modified according to the themes arising in the needs assessment for employees suffering from CANS.

\section{Step 2: create matrices of change objectives}

The purpose of Step 2 was to provide the basis for the intervention by specifying the behavioral change objectives of the intervention. ${ }^{23}$ To analyze the determinants of self-management behavior at work, the Attitude-Social influence-Efficacy (ASE) Model ${ }^{28}$ (comparable to the theory of planned behavior ${ }^{29-31}$ ) was used. This model postulates that intention, the most proximal determinant of behavior, is determined by three independent constructs: attitude, social influence, and perceived behavioral control (self-efficacy). ${ }^{14}$ A model representing how the intervention can influence the determinants of self-management behavior at work, including the impact of barriers, knowledge, and skills, ${ }^{14}$ is presented in Figure 2. The behavioral change objectives of the intervention were formulated on the level of determinants of behavior (attitude, social influence, and self-efficacy), which influence the experienced problems of employees with CANS. The product of Step 2 was a set of matrices of change objectives for personal and environmental determinants, ie, the most immediate target of an intervention. ${ }^{23}$

\section{Step 3: select theory-based intervention methods and practical applications}

Step 3 of the IM included the identification and selection of theory-based methods and practical strategies to change the selected determinants of health behavior. ${ }^{23}$ Intervention methods that corresponded with the change objectives of Step 2 were selected..$^{23}$ For each determinant, appropriate methods were identified from the literature, ${ }^{14,23,30}$ partly based on the methods and practical applications identified in the original training of Detaille et al. ${ }^{14}$

\section{Step 4: organize methods and applications into an intervention program}

The product of this step included a description of the scope and sequence of the components of the intervention, an overview of the program materials, and program protocols. ${ }^{23}$ For the present study, we compared the performance objectives of the self-management training of Detaille ${ }^{15}$ with the performance objectives formulated for the modified version of the training for employees with CANS. The self-management sessions were completed with the development of an eHealth module (the content of which was discussed between $\mathrm{NH}$, $\mathrm{SD}, \mathrm{YH}, \mathrm{JE}, \mathrm{JBS}$, and MN). All possible modifications to the original self-management program were first discussed between NH, SD, and YH; thereafter, all modifications made were discussed between NH, SD, YH, JE, JBS, and MN.

\section{Step 5: plan for adaptation, implementation, and sustainability of the program}

The focus of Step 5 was to develop a plan for the adoption and implementation of the program, including the consideration of program sustainability. ${ }^{23}$ To test the sustainability of the program, an evaluation of the effectiveness of the intervention is necessary. Therefore, several actions were taken to prepare an evaluation of the program in a randomized controlled trial (RCT).

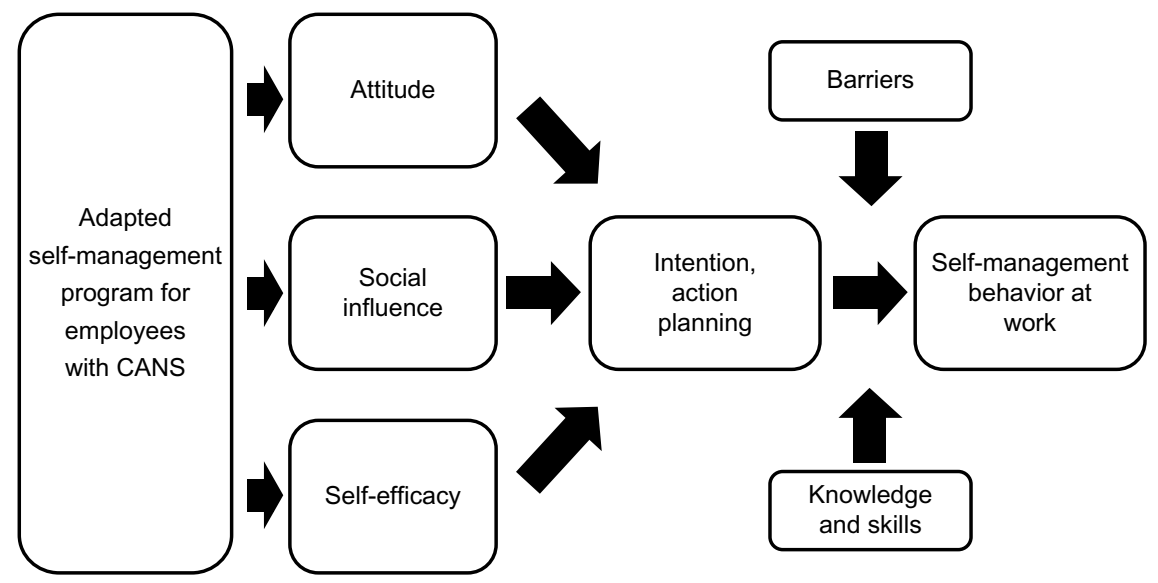

Figure 2 Model representing how the adapted self-management program can influence determinants of self-management behavior at work, including the impact of barriers, knowledge, and skills.

Note: Based on the Attitude-Social influence-Efficacy (ASE) Mode ${ }^{28}$ and adapted from Detaille SI, van der Gulden JW, Engels JA, et al. Using intervention mapping (IM) to develop a self-management programme for employees with a chronic disease in the Netherlands. BMC Public Health. 2010;10:353.14

Abbreviation: CANS, complaints of the arm, neck, and/or shoulder. 


\section{Step 6: generate an evaluation plan}

Step 6 (the generation of an evaluation plan) is actually started with the needs assessment and is developed together with the intervention map. ${ }^{23}$ In this step, we developed a plan for both quantitative and qualitative evaluation of the program integrated in the RCT. The design of the study, a recruitment plan, and promotion materials for the participants were developed.

\section{Results}

\section{Step I: conduct a needs assessment}

The results of the review of the Dutch multidisciplinary guideline for non-specific CANS ${ }^{26}$ showed that several behavioral and environmental factors can influence CANS, and that these should be included in the intervention. Although there is a lack of hard evidence, providing information and knowledge about the causes of CANS to employees suffering from CANS is considered important, as is also the case in patients with a chronic disease. ${ }^{26}$ Furthermore, in the Dutch guideline, etiological and prognostic factors were found to influence the occurrence and cause of CANS and should therefore be addressed in the training; eg, physical factors such as long-standing use of the computer, repetitive work tasks, heavy physical, mental and/or difficult work, unfavorable working times, and the ergonomics of the workplace/posture are important topics addressed in the guideline. ${ }^{26}$ Moreover, psycho-social factors such as high work demands, experienced stress, work satisfaction, experienced support, and personal characteristics are important factors mentioned in the guideline, and should be addressed in the training (when relevant). Also, the role of several behavioral components, which can positively influence the complaints (eg, decreasing workload, taking breaks, muscle relaxation, and physical activity in managing the complaints), were considered important topics that can influence CANS. ${ }^{26}$

The results of the focus groups with employees and experts indicated that the employee's behavior was considered as an important factor related to the onset of symptoms of CANS. It appeared that employees with CANS should be stimulated to search for information about the cause of their complaints, about how to deal with their complaints, and about the manner they can influence their complaints themselves. Therefore, for example, information and skills with regard to setting limits, dealing with stress, and communication were considered important. The results of the focus group sessions with employees with CANS, and with the experts, have been described extensively elsewhere. . $^{16,27}$ Table 1 presents a summary of the results of the focus group sessions with employees with CANS and of the focus group sessions with experts. Figure 3 presents the modified PRECEDE model ${ }^{23,25}$ of behavior, determinants, and environment in employees with CANS, based on the three parts of the needs assessment.

\section{Step 2: create matrices of change objectives}

Based on the needs assessment, the overall goal of the intervention was defined as "self-management behavior at work" with the aim to alleviate the perceived disability of the participants. This outcome is the same as that used by Detaille et al ${ }^{14}$ and did not need to be changed. The objective of the total program was subdivided into performance objectives, presented in the first column of the matrix in Table 2. In this matrix of behavioral change objectives (based on the determinants of behavior identified in the needs assessment), self-management behavior at work was operationalized as follows: 1) to be able to cope with pain, fatigue, limitations, disability and emotional aspects caused by CANS; 2) to be aware of which factors at the workplace cause stress and to adequately deal with work stress by re-organizing work in light of the complaints and according to one's capacity (eg, to modify workload and work pace, to take pauses when needed, and to say "no" when needed); and 3) to be able to communicate effectively about CANS with one's supervisor and colleagues (eg, being able to explain the type of complaints, to ask for facilities at work, and to communicate about a possible change in job demands).

Furthermore the main determinants of behavior change according to the ASE Model ${ }^{28}$ ie, attitude, social influence, and self-efficacy, were operationalized into three categories. Attitude, the first category, was defined as the perceived cognitive and emotional advantages and disadvantages of the health behavior. ${ }^{14}$ Employees with CANS should be aware that the etiology and persistence of CANS are multifactorial, and that individuals can influence the complaints themselves by being aware of the factors that cause stress and taking care of these factors at work. Therefore, awareness is considered very important with regard to a person's attitude.

Social influence, the second category, was defined as (perception of) social support at work and acquiring social support at work. Social influences consist of the perception of others carrying out this type of behavior (social modeling), the norms that people have with respect to these behaviors (social norms), and the support that they perceive from others in carrying out a particular type of behavior, eg, the support 
Table I Summary of the results from the focus group sessions

\section{Focus group sessions with employees with CANS}

- Although employees with CANS tried various ways to reduce their complaints, they still suffered from CANS

- Employees are faced with the challenge to deal with their complaints on a daily basis in both their private and working life

- Employees are not fully aware of the possibilities to influence their symptoms and their own role in triggering and coping with their complaints

- Employees generally are often approaching their individual limits

- Fatigue has a serious impact on the daily life of employees

- Employees have to deal with disrupting physical/socio-environmental factors at work

- Employees have to deal with misunderstandings from supervisor and colleagues

- The identified recurring problem areas endorse the multifactorial etiology of CANS

- There is a need for information about possible (multifactorial) causes of the complaints

- The following needs were mentioned during the focus group sessions: knowledge about exercises, muscle relaxation, working with pain, the work environment, and socio-environmental and personal factors (including work style)

Focus group sessions with experts

- Awareness and behavioral change are found to be important for this group of employees

- The employee's behavior is seen by experts as an important factor related to the onset of symptoms of CANS

- CANS is less related to workplace interior modifications than to the behavior (ie, experiences and the intensity) of the employee at work

- Experts indicate that employees with CANS generally have high demands (on themselves) and are often perfectionists

- Employees who experience a high workload and work pace should learn to be aware when the body gives signals of overloading, and one must react at the appropriate time, such as to take breaks at regular times

- Employees suffering from CANS have difficulty in managing their own health problem and work

- Employees with CANS should be more proactive; in the intervention, bottlenecks should be identified and employees should make their own choices and obtain reassurance. Most experts find it important that the intervention deals with the possible causes of the complaints and the underlying problems that may trigger CANS

- Experts stated that it is important that employees with CANS receive information about topics related to the possible relief of their complaints, such as load and capacity, setting limits, taking breaks, ergonomics, relaxation, social support, social relationships, and physical activity, including exercises

- Moreover, experts find it important that employees are aware of the possible facilities and treatment options within and outside their organization

- Experts seem to see a role for a self-management program for employees with CANS

- Complaints will not always go away, but a self-management program can offer support to these employees in learning how to handle their problems

- The intervention should focus on increasing employees' self-efficacy and empowerment

- Experts indicate that the combination of group sessions and an eHealth module can work extremely well and can strengthen and complement each other

- The self-management intervention is seen as a roadmap, in which participants work on their personal goals, plus the interaction with other participants

- The eHealth module lends itself to providing more information. Participants could then use this information in the sessions in order to fulfil their action plans

Notes: Adapted from Hutting N, Heerkens YF, Engels JA, Staal JB, Nijhuis-van der Sanden MW. Experiences of employees with arm, neck or shoulder complaints: a focus group study. BMC Musculoskelet Disord. 2014;15:141 ${ }^{14}$ and Hutting N, Engels J, Staal J, Heerkens Y, Nijhuis-van der Sanden M. Development of a self-management intervention for employees with complaints of the arm, neck and/or shoulder (CANS): a focus group study with experts. J Occup Med Toxicol. 2015;10:9.27

Abbreviation: CANS, complaints of the arm, neck, and/or shoulder.

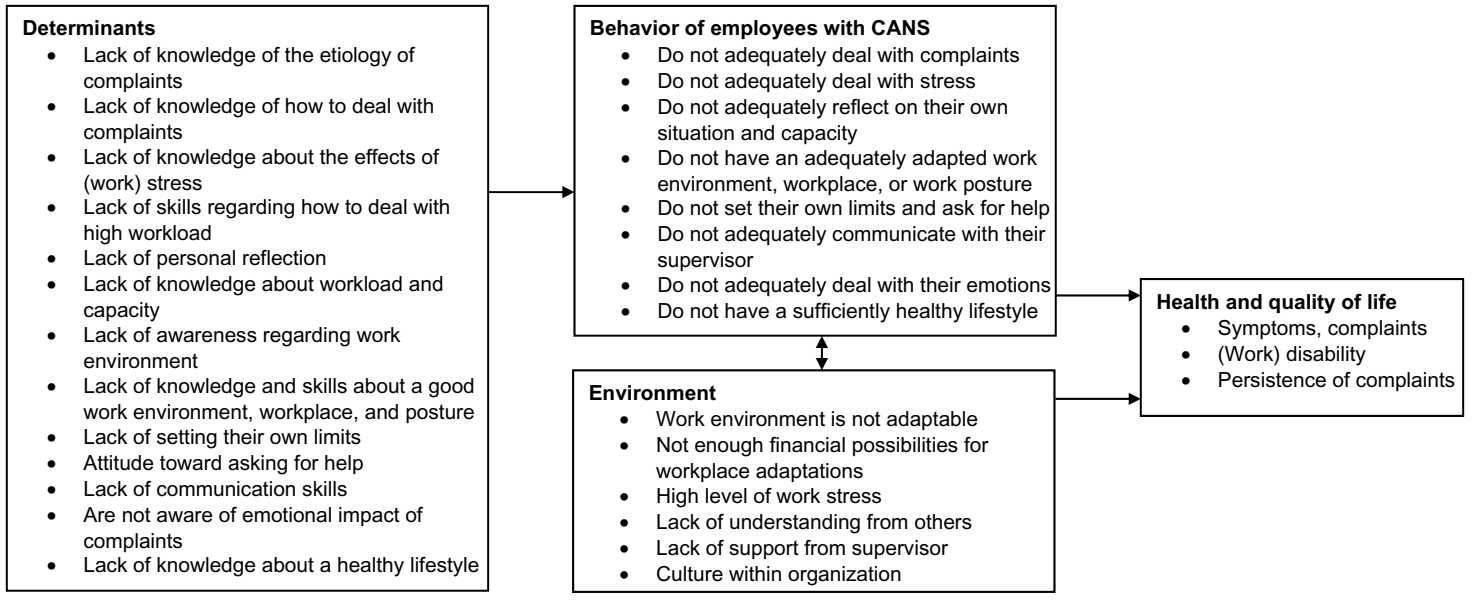

Figure 3 Based on the PRECEDE model of behavior, determinants, and environment in employees with CANS.

Abbreviations: PRECEDE, predisposing, reinforcing, and enabling constructs in educational diagnosis and evaluation; CANS, complaints of the arm, neck, and/or shoulder. 
of the supervisor and colleagues at work. ${ }^{14}$ Employees with CANS often do all the work by themselves, do not seek/ accept support, and do not always communicate about their complaints; therefore, it is important that employees are willing to ask and accept (social) support.

Self-efficacy, the third category, was defined as how confident the person with CANS is about his/her ability to modify the behavior that may cause and trigger CANS, such as perfectionist behavior at work, or to be able to regularly take exercise to deal with the complaint(s). Self-efficacy refers to a person's perception of his/her capability to perform the type of behavior. ${ }^{14}$ The intervention aims to influence all three determinants of behavior, but especially the attitude and self-efficacy at work. Interventions are known to be more effective when focusing on improving a participant's action planning activity, their self-efficacy, and their self-regulatory capabilities, rather than focusing on intention-enhancing risk perceptions. ${ }^{32,33}$

\section{Step 3: select theory-based intervention methods and practical applications}

Table 2 shows the method applied for each determinant that was selected for the development of the intervention. Table 3 describes how these methods were translated into practical strategies. In the original self-management program of Detaille et $\mathrm{al}^{9,14}$ goal setting is an important method for increasing self-efficacy, and action planning is part of the ASE model. ${ }^{28}$ Through goal setting (action plans), the participant can focus on working on their self-efficacy. ${ }^{14}$ Goal setting leads to better performance, because individuals with explicit goals exert themselves to a greater extent and persevere in their tasks. ${ }^{34,35}$ Action planning is an important component of self-management interventions, with successful completion being associated with improved health and self-efficacy outcomes. ${ }^{36} \mathrm{~A}$ goal should be formulated according to the SMART (specific, measurable, attainable, realistic, and timely) criteria, and should be stated in terms of behavior. ${ }^{14}$ Each week, participants formulate one or more goals with regard to self-management behavior, which they intend to accomplish during the following week. After formulating the plan, the participants has to state how confident they are that they will carry out the action plan. ${ }^{14}$ If the level of confidence is below 7 (on a 1-10 scale), the participant is asked about challenges or problems, and suggestions are offered; thereafter, the participant may change his/her plan. ${ }^{36,37}$ The ASE model also indicates that barriers can influence the outcome of the action planning, and that these barriers should be identified and resolved. ${ }^{28}$ During the

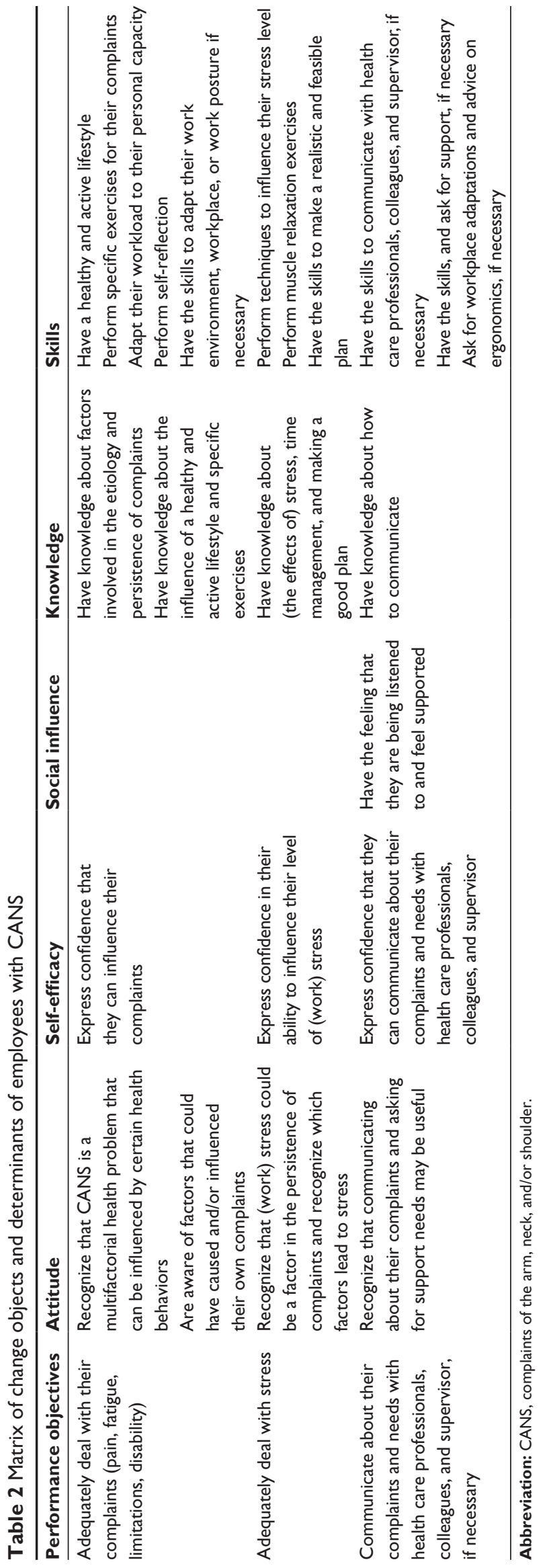


Table 3 Overview of the selected theoretical methods and practical strategies for use in the intervention

\begin{tabular}{|c|c|c|}
\hline Determinant & Method & Strategy \\
\hline \multirow[t]{2}{*}{ Attitude } & Belief selection ${ }^{62}$ & $\begin{array}{l}\text { Through awareness exercises and discussions, participants learn to identify current } \\
\text { beliefs and to strengthen positive beliefs and weaken negative beliefs. Moreover, } \\
\text { new beliefs are introduced }\end{array}$ \\
\hline & Modeling ${ }^{63}$ & Participants are reinforced by the attitudes of other participants \\
\hline \multirow[t]{4}{*}{ Self-efficacy } & Goal setting ${ }^{64}$ & $\begin{array}{l}\text { Participants formulate a long-term goal and weekly short-term goals. Through } \\
\text { weekly action plans, participants work on their formulated goals }\end{array}$ \\
\hline & Modeling 63 & Participants are reinforced by the achievements of other participants \\
\hline & Public commitment ${ }^{65}$ & Participants discuss their action plans and formulated goals with other participants \\
\hline & Feedback $^{66}$ & $\begin{array}{l}\text { Participants receive feedback on their action plans, formulated goals, and } \\
\text { achievements from the trainer and other participants }\end{array}$ \\
\hline \multirow[t]{4}{*}{ Social influence } & Enhance assertiveness ${ }^{30}$ & $\begin{array}{l}\text { Through awareness exercises, discussion, knowledge, skills, and goal setting, } \\
\text { participants' assertiveness with colleagues, supervisor, and health care professionals } \\
\text { is enhanced }\end{array}$ \\
\hline & Modeling 63 & Participants are reinforced by the achievements of other participants \\
\hline & $\begin{array}{l}\text { Stimulate communication to } \\
\text { mobilize social support }{ }^{67}\end{array}$ & $\begin{array}{l}\text { Through information about communication and practical skills, participants are } \\
\text { stimulated to communicate about their complaints with colleagues, supervisor, and } \\
\text { health care professionals, and therefore feel increased social support }\end{array}$ \\
\hline & $\begin{array}{l}\text { Provide opportunities for social } \\
\text { comparison }^{68}\end{array}$ & $\begin{array}{l}\text { Participants can compare themselves with other participants (upward as well as } \\
\text { downward comparison) }\end{array}$ \\
\hline \multirow[t]{5}{*}{ Knowledge } & Information 30,69 & $\begin{array}{l}\text { Participants get information about subjects related to the relevant topics (as well as } \\
\text { in the group sessions, in the group sessions manual, and from the eHealth module) }\end{array}$ \\
\hline & Active learning ${ }^{70}$ & $\begin{array}{l}\text { Participants are encouraged to perform exercises and to learn on the basis of their } \\
\text { action plans }\end{array}$ \\
\hline & Discussion ${ }^{70}$ & $\begin{array}{l}\text { Participants discuss several topics derived from the group sessions and eHealth } \\
\text { module during the group sessions }\end{array}$ \\
\hline & Consciousness raising & $\begin{array}{l}\text { Participants get information and feedback on causes, consequences, and } \\
\text { alternatives of their behavior }\end{array}$ \\
\hline & Self (re)evaluation ${ }^{71}$ & $\begin{array}{l}\text { Participants are stimulated to become aware of their behavior in relation to risk } \\
\text { factors for complaints }\end{array}$ \\
\hline \multirow[t]{5}{*}{ Skills } & Guided practice ${ }^{63}$ & $\begin{array}{l}\text { Participants can look up exercises in the eHealth module and can get feedback } \\
\text { during the sessions }\end{array}$ \\
\hline & Modeling 63 & Participants are reinforced by the achievements of other participants \\
\hline & Skills training & Participants practice with communication skills during the sessions \\
\hline & Feedback $^{66}$ & $\begin{array}{l}\text { Participants get feedback on their behavior, skills, and action plans from the trainer } \\
\text { and participants }\end{array}$ \\
\hline & Self-monitoring of behavior ${ }^{72}$ & Participants are stimulated to monitor and reflect on their behavior \\
\hline
\end{tabular}

next session, the participants report whether or not they have accomplished their action plan, and give an account of the solving of any problems that might have arisen. ${ }^{14}$

\section{Step 4: organize methods and applications into an intervention program}

The product of Step 4 resulted in the final program plan. Self-management at work at the individual level is targeted through the development of 6-weekly group sessions of 2.5 hours each. An overview of the program is presented in Table 4. Compared with the original program ${ }^{14}$ for employees with a chronic somatic disease, the developed program is slightly adapted to the (work) situation of employees with CANS. Two new topics are added to the training. Firstly, the core quadrant (qualities, pitfalls, challenges, and allergies) ${ }^{38}$ is added to gain insight into the participants' qualities and pitfalls. Core quadrants focus on what is right and is going well. Each core quality has its positive side and its negative side, which can be a persons' weak spot. Such a pitfall is frequently a source of conflict, irritation, and tension to other people in that person's environment. This is particularly so if the pitfall turns out to be another person's allergy. ${ }^{38}$ Secondly, a topic about time management is added because of the high level of (work) demands of employees with CANS. Moreover, the development of a mind map is added to the topic of "making plans for the future", and an interactive topic about exercises with a movement scientist/ physical therapist is also added. ${ }^{39}$ All the original topics used by Detaille et al ${ }^{14}$ are retained in the self-management sessions. The topic on nutrition is shortened because, although 
Table 4 Topics of the group sessions and structure of the eHealth module

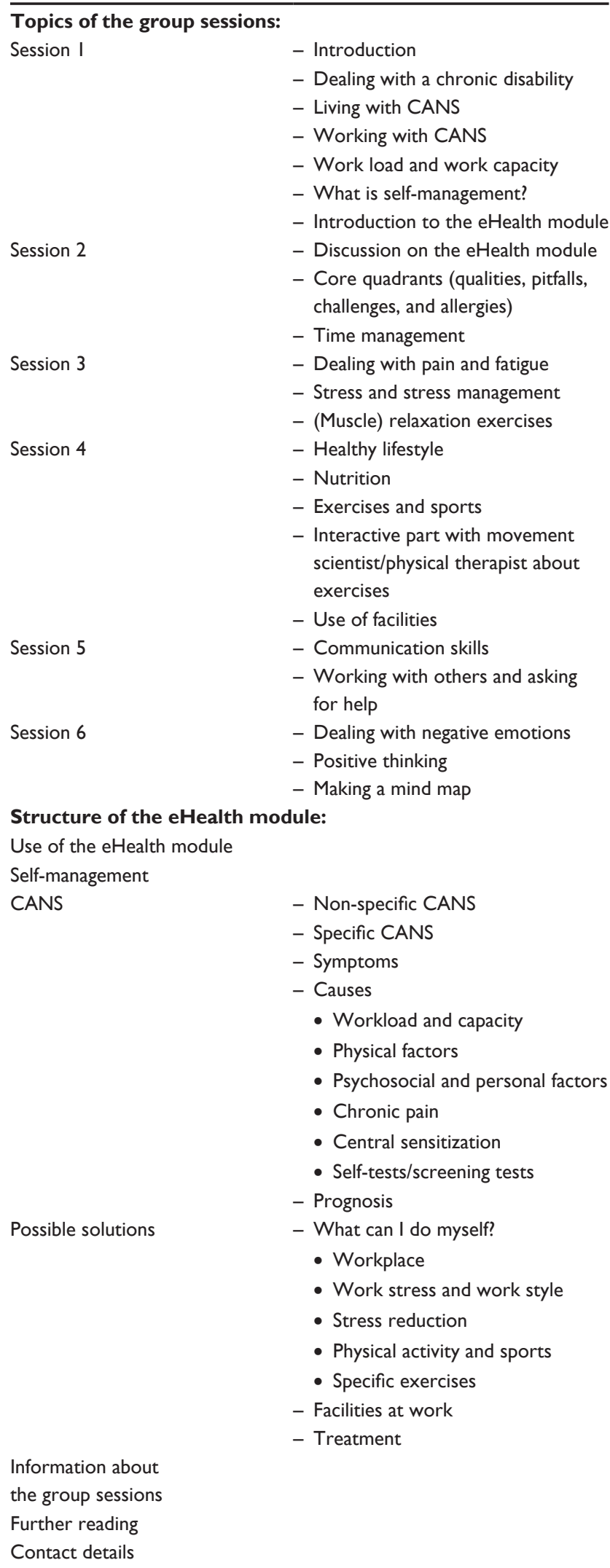

Abbreviation: CANS, complaints of the arm, neck, and/or shoulder. it is related to a healthy lifestyle, it is less specifically related to CANS. Furthermore, the original program topics are adapted with specific examples related to the work situation of employees suffering from CANS, and the order of several topics and sessions is changed. As a result of the needs assessment, the self-management sessions are seen as the main focus of the intervention, with the support of the eHealth. The self-management sessions are complemented by an eHealth module accessible for the participants (via a personal login) for a period of 1 year. The content of the eHealth module is presented in Table 4 . The more general self-management themes (which often need explanation, group discussion, and training) are addressed in the selfmanagement sessions; the more specific CANS-related themes are mainly addressed in the eHealth module, because the relevance of these themes can differ widely between participants. Participants can use this information in the sessions to fulfil their action plans. The self-management sessions and the eHealth module complement each other, forming an integrated program of self-management. The structure of the eHealth module is linked with references to topics in the self-management sessions; this stimulates the use of the eHealth module and makes it easier to find related topics.

\section{Step 5: plan for adoption, implementation, and sustainability of the program}

In Step 5 of the IM process, inclusion criteria for the participants were defined, and a plan was made for the recruitment of participants for an evaluation study. Several actions can be taken to stimulate the participation of employees suffering from CANS within the participating organizations. During the process of developing the intervention, a steering committee of stakeholders was set up to facilitate short- and long-term implementation of the intervention. The final program was tested among the first groups of participants. Trainers were recruited, and recruitment materials were developed by $\mathrm{NH}, \mathrm{YH}, \mathrm{JE}$, JBS, and MN. All trainers received the correct training and sufficient instructions to guide the course. The inclusion/ exclusion criteria and recruitment plan are described in detail elsewhere. ${ }^{24}$

The course manuals for the participants and trainers were adapted by NH and SD. The content of the eHealth module was developed by NH, SD, YH, JE, JBS, and MN. The technical aspects of the eHealth module were developed in collaboration with an external party. Trainers were 
recruited from the staff of the Hogeschool van Arnhem en Nijmegen (HAN) University of Applied Sciences and the Radboud University Medical Center. All trainers were trained by $\mathrm{SD}$, the developer of the original program for workers with a chronic disease and who is also experienced in the development/implementation of self-management programs. Depending on the number of participants, sessions can be facilitated by one or two trainers. No major modifications were made after testing the program with the first group of participants.

\section{Step 6: generate an evaluation plan}

The study protocol, including the evaluation plan, is described in detail elsewhere. ${ }^{24}$ The design of the study, a recruitment plan, and the promotion materials for participants were approved by the Medical Ethics Committee of the Radboud University Medical Center (registration number 2012/319). The RCT is registered with the Dutch Trial Register (http://www.trialregister.nl; registration number NTR3816). In short, the effect evaluation will consist of an RCT with a 12-month follow-up period. Data are collected at baseline and at 3, 6, and 12 months. The primary outcome measure will be the self-reported disability (in the previous week) of arm, shoulder, and hand, measured with the Disabilities of the Arm, Shoulder and Hand (DASH) questionnaire. ${ }^{40}$ Secondary outcome measures are related to absenteeism, presenteeism, ${ }^{41,42}$ pain, ${ }^{43}$ self-efficacy (at work),${ }^{15,44}$ fatigue,${ }^{45}$ burnout features,${ }^{46}$ work style,${ }^{47}$ pace and amount of work, ${ }^{48}$ relations with colleagues/supervisors, ${ }^{48}$ need for recovery, ${ }^{48}$ participation and empowerment at the workplace, ${ }^{48}$ quality of life, ${ }^{49}$ self-reflection and insight, ${ }^{50}$ and employees' opinion about working with complaints, ${ }^{15}$ as well as to self-management at work, the use of health care interventions, participation in sport, and limitations experienced in work activities and work capacity. Power analysis ${ }^{24}$ revealed a necessity of a sample size of 71 participants in each group, assuming a dropout rate of $20 \%$. This implies that a total of 142 patients will be needed to detect a clinically relevant difference ${ }^{51}$ in DASH scores with a power of 0.90 and an $\alpha$ of 0.05 .

Moreover, a qualitative evaluation with approximately 30 participants will be conducted at the end of the selfmanagement sessions. These participants will be interviewed to evaluate their reasons to participate, their expectations, benefits, future expectations, and experiences with the action plans, group sessions, and eHealth module. Furthermore, participants will be asked for their ideas about how the intervention might be improved.

\section{Discussion}

The current paper describes the developmental process, the content, and planned evaluation of a theory- and practicebased self-management intervention for employees in the Netherlands suffering from nonspecific CANS. IM is a helpful tool to screen existing interventions and tailor the intervention for a specific population. ${ }^{14,52,53}$ Following the six steps of the IM protocol, ${ }^{20,23}$ the original intervention developed by Detaille et $\mathrm{al}^{9,14,15}$ was adapted to fit the needs of the target population.

The overall outcome of the intervention was defined as self-management behavior at work to improve the perceived disability of the participants, and for this, a matrix of behavior change objectives and personal behavior determinants was developed. The behavior change objectives were related to the factors of the ASE Model. ${ }^{28}$ The intervention aims to influence all three determinants of behavior, but especially the attitude to and self-efficacy at work. Interventions are known to be more effective if they focus on improving a participant's action planning activity and their self-efficacy and self-regulatory capabilities, rather than focusing on intention-enhancing risk perceptions. ${ }^{32,33}$ In the study of Detaille et al, ${ }^{9}$ the attitude toward self-management at work (enjoyment) improved after 8 months $(P=0.03)$ in the intervention group. Moreover, a qualitative evaluation of that study indicates that the intervention generally had a positive effect on the employees' working life and wellbeing, and that participants would recommend the program to others. ${ }^{15}$

The IM process resulted in a self-management program for employees suffering from CANS, consisting of six group sessions and a complementary eHealth module. Because the use of the eHealth module may vary between participants, the group sessions also address (to some extent) all of the topics identified in the needs assessment. By adding an eHealth module, we expect that higher educated employees will also benefit from the intervention; in the intervention of Detaille et al, ${ }^{9}$ lower educated workers in the intervention group developed better physical health quality (SF-12) compared with the lower educated workers in the control group.

A possible strength of the developed intervention is the thorough adaptation and tailoring of an existing selfmanagement intervention to fit the needs of employees with CANS. Moreover, two new topics were added to the training (the core quadrant and time management), and a mind map was developed and added to the topic making plans for the future.

There is inconsistent evidence for the effects of self-management programs for patients with chronic 
musculoskeletal pain, ${ }^{39,54,55}$ and there is some evidence that group-delivered short programs ( $<8$ weeks) with a health care professional have the best potential. ${ }^{39}$ Moreover, group sessions can stimulate modeling and reinforcement of other participants' activities, and participants can compare themselves with other participants. Also, discussion is stimulated, and participants can learn from the experiences of other participants. Therefore, we expect that the developed program, consisting of six group sessions and with an additional interactive topic on exercises with a movement scientist/physical therapist, could be beneficial for employees with CANS.

In addition to the sessions, the eHealth module was developed to provide more thorough tailoring of the intervention. It is probably possible to tailor the program for employees with other musculoskeletal disorders, by adapting the eHealth module and only slightly adapting the content of the group sessions. Another possible strength of the developed intervention is the use of the ASE Model, ${ }^{28}$ which was also used in the original intervention of Detaille et $\mathrm{al}^{14}$ and in other IM intervention developments, ${ }^{52}$ together with the use of methods and strategies for behavior change (Table 3), which emphasizes the theory-based character of the intervention. Also, the integration of expert opinion, not only regarding the needs of employees with CANS and the content of the intervention, but also concerning self-management and the development of the eHealth module, can be seen as a strength of the model's design. Expert opinion is increasingly used in the development of self-management interventions. ${ }^{56,57}$

Although the group sessions will last only 6 weeks, the eHealth module is accessible for 1 year, allowing participants to review the topics and exercises of the program; this may stimulate participants to maintain their behavioral changes in the long term. Moreover, in the future, the eHealth module can be converted into an online self-management tool, or can be used as an information tool for employees with CANS. It is reported that online self-management programs can be useful and beneficial. ${ }^{58-60}$

Another major strength is the diversity of the intervention topics, which is based on the combination of group sessions (with more generic themes), the eHealth module (with more specific themes; Table 3), and the use of personal action plans. As mentioned, action planning is an effective component of self-management interventions, ${ }^{36}$ and participants have indicated that working with an action plan is both useful and effective. ${ }^{15}$ Personalized action plans can be an important component with regard to the multifactorial etiology of CANS; in this way, all participants can work on their own goals. By dividing the topics between the group sessions (more general topics) and eHealth module (more specific topics), and with the use of action plans, we aimed to make the program both interesting and useful for each participant.

The fact that part of the intervention will be available via the computer might be seen as a weakness of the intervention, especially among employees whose complaints might (partly) be caused by use of the computer. However, we tried to address this issue by making use of the eHealth module optional rather than mandatory. Another possible weakness is that the views of employers and supervisors were not taken into account in the development of the intervention. Focus group sessions with employees revealed some issues with regard to their employers and supervisors. Therefore, as indicated by Detaille et al, ${ }^{14}$ another point of discussion is whether a self-management program for the employee is sufficient to facilitate the workability of such a program for employees, or whether the physical and social working environment should also be the object of an intervention. We assume that not (only) the work environment, but also the personal characteristics of employees with CANS, are important when considering the causes of complaints and when dealing with complaints. ${ }^{16}$ Self-management interventions focus primarily on encouraging participants to be involved with and to control their own treatment, as well as improving their understanding of how their condition and treatment affect their lives. ${ }^{61}$ Therefore, the intervention focuses on empowerment of the participating employees.

Another limitation is that the intervention was developed to suit the participants' needs in different stages of behavioral change; also, participants work on different behavioral goals. Therefore, the program is not tailored for participants according to a stage of behavioral change and one specific behavioral goal. In the development group, there was some discussion about the inclusion of the subject nutrition in the intervention. This topic was part of the original selfmanagement program, ${ }^{14}$ but seems to be less important with regard to employees with CANS. Eventually, it was decided to address this topic only briefly, because a healthy lifestyle is important for everyone and especially for individuals suffering from stress and fatigue.

\section{Conclusion}

In the present study, a self-management program developed by Detaille et $\mathrm{al}^{14}$ was adapted and tailored for employees with non-specific CANS. By modifying and adding elements, including an eHealth module, and by following the IM protocol, we systematically adapted the original program ${ }^{14}$ to suit 
the needs of the target group. This resulted in a theory- and practice-based self-management program, including an eHealth module. This program is expected to benefit employees with non-specific CANS, and its effectiveness will later be evaluated in an RCT.

\section{Acknowledgment}

This study was funded by the Netherlands Organisation for Health Research and Development (ZonMw) (grant number 208030004).

\section{Disclosure}

The authors report no conflicts of interest in this work.

\section{References}

1. Miedema HS, Feleus A. Richtlijn 'Aspecifieke klachten arm, nek en/ of schouders' [Guideline 'Non-specific symptoms of arm, neck and/or shoulders']. Ned Tijdschr Geneeskd. 2013;157(21):A6249. Dutch.

2. Martimo KP, Shiri R, Miranda H, Ketola R, Varonen H, Viikari-Juntura E. Self-reported productivity loss among workers with upper extremity disorders. Scand J Work Environ Health. 2009;35(4):301-308.

3. Harrington CB, Siddiqui A, Feuerstein M. Workstyle as a predictor of pain and restricted work associated with upper extremity disorders: a prospective study. J Hand Surg Am. 2009;34(4):724-731.

4. Buckle P, Devereux J. Work-Related Neck and Upper Limb Musculoskeletal Disorders. Luxembourg: European Agency for Safety and Health at Work; 1999.

5. Bernaards CM, Bosmans JE, Hildebrandt VH, van Tulder MW, Heymans MW. The cost-effectiveness of a lifestyle physical activity intervention in addition to a work style intervention on recovery from neck and upper limb symptoms and pain reduction in computer workers. Occup Environ Med. 2011;68(4):265-272.

6. Feleus A, Bierma-Zeinstra SM, Miedema HS, Bernsen RM, Verhaar JA, Koes BW. Incidence of non-traumatic complaints of arm, neck and shoulder in general practice. Man Ther. 2008;13(5):426-433.

7. Keijsers E, Feleus A, Miedema HS, Koes BW, Bierma-Zeinstra SM. Psychosocial factors predicted nonrecovery in both specific and nonspecific diagnoses at arm, neck, and shoulder. J Clin Epidemiol. 2010; 63(12):1370-1379.

8. Verhagen AP, Bierma-Zeinstra SM, Burdorf A, Stynes SM, de Vet HC, Koes BW. Conservative interventions for treating work-related complaints of the arm, neck or shoulder in adults [review]. Cochrane Database Syst Rev. 2013;12:CD008742.

9. Detaille SI, Heerkens YF, Engels JA, van der Gulden JW, van Dijk FJ. Effect evaluation of a self-management program for Dutch workers with a chronic somatic disease: a randomized controlled trial. J Occup Rehabil. 2013;23(2):189-199.

10. Meijer EM, Sluiter JK, Frings-Dresen MH. Is workstyle a mediating factor for pain in the upper extremity over time? J Occup Rehabil. 2008;18(3):262-266.

11. Cole DC, Van Eerd D, Bigelow P, Rivilis I. Integrative interventions for MSDs: nature, evidence, challenges and directions. J Occup Rehabil. 2006;16(3):359-374.

12. Bongers PM, IJmker S, van den Heuvel S, Blatter BM. Epidemiology of work related neck and upper limb problems: psychosocial and personal risk factors (part I) and effective interventions from a bio behavioural perspective (part II). J Occup Rehabil. 2006;16(3):279-302.

13. Esmaeilzadeh S, Ozcan E, Capan N. Effects of ergonomic intervention on work-related upper extremity musculoskeletal disorders among computer workers: a randomized controlled trial. Int Arch Occup Environ Health. 2014;87(1):73-83.
14. Detaille SI, van der Gulden JW, Engels JA, Heerkens YF, van Dijk FJ. Using intervention mapping (IM) to develop a self-management programme for employees with a chronic disease in the Netherlands. $B M C$ Public Health. 2010;10:353.

15. Detaille SI. Building a Self-management Program for Workers with a Chronic Somatic Disease [doctoral thesis]. Nijmegen: Ipskamp Drukkers BV; 2012.

16. Hutting N, Heerkens YF, Engels JA, Staal JB, Nijhuis-van der Sanden MW. Experiences of employees with arm, neck or shoulder complaints: a focus group study. BMC Musculoskelet Disord. 2014;15:141.

17. Kuijpers W, Groen WG, Aaronson NK, van Harten WH. A systematic review of web-based interventions for patient empowerment and physical activity in chronic diseases: relevance for cancer survivors. J Med Internet Res. 2013;15(2):e37.

18. Ahern DK. Challenges and opportunities of eHealth research. Am J Prev Med. 2007;32(5 Suppl):S75-S82.

19. Eysenbach G. The law of attrition. J Med Internet Res. 2005; 7(1):e11.

20. Bartholomew LK, Parcel GS, Kok G. Intervention mapping: a process for developing theory- and evidence-based health education programs. Health Educ Behav. 1998;25(5):545-563.

21. Bartholomew LK, Parcel GS, Kok G, Gottlieb NH. Planning Health Promotion Programs: An Intervention Mapping Approach. San Francisco: Jossey-Bass, Inc; 2006.

22. Vonk Noordegraaf A, Huirne JA, Pittens CA, et al. eHealth program to empower patients in returning to normal activities and work after gynecological surgery: intervention mapping as a useful method for development. J Med Internet Res. 2012;14(5):e124.

23. Bartholomew L, Parcel G, Kok G, Gottlieb N, Fernández M. Planning Health Promotion Programs. An Intervention Mapping Approach. 3rd ed. San Francisco: Jossey-Bass, Inc.; 2011.

24. Hutting N, Staal JB, Heerkens YF, Engels JA, Nijhuis-van der Sanden MW. A self-management program for employees with complaints of the arm, neck or shoulder (CANS): study protocol for a randomized controlled trial. Trials. Epub August 16, 2013.

25. Green L, Kreuter M. Health Program Planning: An Educational and Ecological Approach. 4th ed. New York: McGraw-Hill Education; 2005.

26. Beumer A, De Bie RA, Ten Cate A, Doornbos N. Multidisciplinaire richtlijn aspecifieke Klachten Arm, Nek en/of Schouders [Multidisciplinary guideline non-specific complaints of arm, neck and/or shoulders]. Amersfoort: Koninklijk Nederlands Genootschap voor Fysiotherapie (KNGF); 2012. Dutch.

27. Hutting N, Engels J, Staal J, Heerkens Y, Nijhuis-van der Sanden M. Development of a self-management intervention for employees with complaints of the arm, neck and/or shoulder (CANS): a focus group study with experts. J Occup Med Toxicol. 2015;10:9.

28. De Vries H, Mudde A. Predicting stage transitions for smoking cessation applying the Attitude-Social influence-Efficacy model. Psychol Health. 1998;13:369-385.

29. Ajzen I. The theory of planned behavior. Organ Behav Hum Decis Process. 1991;50:179-211.

30. Brug J, Assema P, Lechner L. Gezondheidsvoorlichting en gedragsverandering. Een planmatige aanpak. [Health education and behavioral change: a systematic approach] Assen: Van Gorcum; 2008. Dutch.

31. Ajzen I. Attitudes, Personality and Behavior. 2nd edition. London: Milton Keynes Open University Press; 2005.

32. Lippke S, Ziegelmann J, Schwarzer R. Behavioral intentions and action plans promote physical exercise: a longitudinal study with orthopedic rehabilitation patients. J Sport Exerc Psychol. 2004;26:470-483.

33. Bodenheimer T, Lorig K, Holman H, Grumbach K. Patient selfmanagement of chronic disease in primary care. JAMA. 2002;288(19): 2469-2475.

34. Latham G, Locke E, Fassina N. The high performance cycle: standing the test of time. In: Sonnentag S, editor. The Psychological Management of Individual Performance. A Handbook in the Psychology of Management in Organizations. Chichester: John Wiley and Sons; 2002: 201-228. 
35. Locke EA, Latham GP. Building a practically useful theory of goal setting and task motivation. A 35-year odyssey. Am Psychol. 2002;57(9):705-717.

36. Lorig K, Laurent DD, Plant K, Krishnan E, Ritter PL. The components of action planning and their associations with behavior and health outcomes. Chronic Illn. 2014;10(1):50-59.

37. Lorig K. Action planning: a call to action. J Am Board Fam Med. 2006;19(3):324-325.

38. Ofman D. Core Qualities: A Gateway to Human Resources. Cyan Communications; 2004.

39. Carnes D, Homer KE, Miles CL, et al. Effective delivery styles and content for self-management interventions for chronic musculoskeletal pain: a systematic literature review. Clin J Pain. 2012;28(4):344-354.

40. Beaton DE, Katz JN, Fossel AH, Wright JG, Tarasuk V, Bombardier C. Measuring the whole or the parts? Validity, reliability, and responsiveness of the Disabilities of the Arm, Shoulder and Hand outcome measure in different regions of the upper extremity. J Hand Ther. 2001;14(2): 128-146.

41. Koopman C, Pelletier KR, Murray JF, et al. Stanford presenteeism scale: health status and employee productivity. J Occup Environ Med 2002;44(1):14-20.

42. Hutting N, Engels JA, Heerkens YF, Staal JB, Nijhuis-van der Sanden MW. Development and measurement properties of the Dutch version of the Stanford Presenteeism Scale (SPS-6). J Occup Rehabil. 2014;24(2) 268-277.

43. Sullivan M, Bishop S, Pivik J. The Pain Catastrophizing Scale: development and validation. Psychol Assess. 1995;7:524-532.

44. Teeuw B, Schwarzer R, Jerusalem M. Dutch adaptation of the general self-efficacy scale. 1994; Available from: http://userpage.fu-berlin. de/ health/dutch.htm. Accessed May 12, 2013.

45. Vercoulen JH, Swanink CM, Fennis JF, Galama JM, van der Meer JW, Bleijenberg G. Dimensional assessment of chronic fatigue syndrome. J Psychosom Res. 1994;38(5):383-392.

46. van Dierendonck D, Schaufeli WB, Buunk BP. Burnout and inequity among human service professionals: a longitudinal study. $J$ Occup Health Psychol. 2001;6(1):43-52.

47. Feuerstein M, Nicholas RA. Development of a short form of the Workstyle measure. Occup Med (Lond). 2006;56(2):94-99.

48. van Veldhoven M, Meijman TF, Broersen JPJ, Fortuin RJ. Handleiding VBBA [Manual VBBA]. SKB Vragenlijst Services; 2002. Dutch.

49. Ware J, Kosinski M, Keller SD. A 12-Item Short-Form Health Survey: construction of scales and preliminary tests of reliability and validity. Med Care. 1996;34(3):220-233.

50. Grant AM, Franklin J, Langford P. The Self-reflection and Insight scale: a new measure of private self-consciousness. J Soc Behav Pers. 2001;30:821-836.

51. Bron C, de Gast A, Dommerholt J, Stegenga B, Wensing M, Oostendorp RA. Treatment of myofascial trigger points in patients with chronic shoulder pain: a randomized, controlled trial. BMC Med 2011;9:8.

52. van Oostrom SH, Anema JR, Terluin B, Venema A, de Vet HC, van Mechelen W. Development of a workplace intervention for sick-listed employees with stress-related mental disorders: intervention mapping as a useful tool. BMC Health Serv Res. 2007;7:127.

53. Vermeulen SJ, Anema JR, Schellart AJ, van Mechelen W, van der Beek AJ. Intervention mapping for development of a participatory return-to-work intervention for temporary agency workers and unemployed workers sick-listed due to musculoskeletal disorders. $B M C$ Public Health. 2009;9:216.

54. Nolte S, Osborne RH. A systematic review of outcomes of chronic disease self-management interventions. Qual Life Res. 2013;22(7): 1805-1816.
55. Du S, Yuan C, Xiao X, Chu J, Qiu Y, Qian H. Self-management programs for chronic musculoskeletal pain conditions: a systematic review and meta-analysis. Patient Educ Couns. 2011;85(3):e299-e310.

56. Johnston V, Strong J, Gargett S, Jull G, Ellis N. Enhancing the vocational outcomes of people with chronic disabilities caused by a musculoskeletal condition: development and evaluation of content of self-management training modules. Work. 2014;49(3):455-464.

57. Varekamp I, Haafkens JA, Detaille SI, Tak PP, van Dijk FJ. Preventing work disability among employees with rheumatoid arthritis: what medical professionals can learn from the patients' perspective. Arthritis Rheum. 2005;53(6):965-972.

58. Bantum EO, Albright CL, White KK, et al. Surviving and thriving with cancer using a Web-based health behavior change intervention: randomized controlled trial. J Med Internet Res. 2014;16(2):e54.

59. Lorig K, Ritter PL, Plant K, Laurent DD, Kelly P, Rowe S. The South Australia health chronic disease self-management Internet trial. Health Educ Behav. 2013;40(1):67-77.

60. Choi NG, An S, Garcia A. A feasibility study of low-income homebound older adults' participation in an online chronic disease self-management program. Home Health Care Serv Q. 2014;33(2):106-120.

61. Newman S, Steed L, Mulligan K. Self-management interventions for chronic illness. Lancet. 2004;364(9444):1523-1537.

62. Fishbein M, Ajzen I. Predicting and change behaviour: The Reasoned Action Approach. New York: Taylor \& Francis; 2010.

63. McAlister A, Perry C, Parcel G. How individuals, environments, and health behaviors interact: Social Cognitive Theory. In: Glanz K, Rimer K, Viswanath K, eds. Health beavior and education. 4th ed. San Francisco: Jossey-Bass; 2008:169-188.

64. Latham G, Edwin A, Locke E. New Developments in and Directions for Goal-Setting Research. European Psychologist. 2007;12(4):290-300.

65. Ajzen I, Czasch C, Flood MG. From Intentions to Behavior: Implementation Intention, Commitment, and Conscientiousness. Journal of Applied Social Psychology. 2009;39:1356-1372.

66. Kazdin A. Behavior modification in applied settings. 6th ed. Long Grove, IL: Waveland Press; 2008.

67. Heaney C, Israel B. Social networks and social support. In: Glanz KR, BK; Viswanath, K, ed. Health behavior and health education: Theory, research, and practice. 4th ed. San Francisco: Jossey-Bass; 2008:189-210.

68. Suls JM, R; Wheeler, L. Social Comparison: Why, with Whom, and with What Effect? Current Directions in Psychological Science. 2002;11(5):159-163.

69. Kools M, Ruiter RA, van de Wiel MW, Kok G. Increasing readers' comprehension of health education brochures: a qualitative study into how professional writers make texts coherent. Health education \& behavior: the official publication of the Society for Public Health Education. December 2004;31(6):720-740.

70. Petty R, Barden J, SC W. The Elaboration Likelihood Model of Persuasion: Developing health promotions for sustained behavioral change. In: DiClemente R, Crosby R, Kegler M, eds. Emerging theories in health promotion practice and research. 2nd ed. San Francisco: Jossey-Bass; 2009:185-214.

71. Prochaska J, Redding C, Evers K. The Transtheoretical Model and stages of change. In: Glanz K, Rimer B, Viswanath K, eds. Health behavior and health education: theory, research, and practice. 4th ed. San Francisco: Jossey-Bass; 2008:92-121.

72. Creer T. Self-management of chronic ilness. In: Boekaerts M, Pintrich P, Zeidner M, eds. Handbook of self-regulation. San Diego: Academic Press; 2000:601-629. 


\section{Publish your work in this journal}

The Journal of Multidisciplinary Healthcare is an international, peerreviewed open-access journal that aims to represent and publish research in healthcare areas delivered by practitioners of different disciplines. This includes studies and reviews conducted by multidisciplinary teams as well as research which evaluates the results or conduct of such teams or

healthcare processes in general. The journal covers a wide range of areas and welcomes submissions from practitioners at all levels, from all over the world. The manuscript management system is completely online and includes a very quick and fair peer-review system. Visit http://www.dovepress.com/testimonials.php to read real quotes from published authors.

Submit your manuscript here: http://www.dovepress.com/journal-of-multidisciplinary-healthcare-journal 